\title{
Novel markings on the unit package of uncuffed pediatric tracheal tubes
}

\author{
Swapnil Awsar, MD • Karen Brown, MD
}

Received: 12 February 2019/Revised: 5 March 2019/Accepted: 6 March 2019/Published online: 15 March 2019

(c) Canadian Anesthesiologists' Society 2019

\section{To the Editor,}

The purpose of this letter is to highlight a new marking convention appearing on the unit packages of uncuffed tracheal tubes (TTs) (Figure). In 1974, Loew and Thibeault $^{1}$ described two marking conventions for uncuffed TTs, namely the black safety line (to be placed at the level of the vocal cords) and the insertion depth marks (to be documented at the lips or nares). In a study of 28 infants the TT tip was positioned in the middle third of the trachea, with this method preventing endobronchial intubation.

Subsequently, the International Organization for Standardization (ISO) mandated the marking of insertion depth marks at $1-\mathrm{cm}$ intervals from the TT tip. Nevertheless, it was silent on the marking of the black safety line(s). Voluntarily, manufacturers marked the black safety line(s), but they did not standardize the marking convention. Worldwide, both neonatologists and anesthesiologists have identified this lack of standardization as a source of imprecision, confusion, and morbidity. In its 2016 revision of the medical device standard for TTs and connectors, ISO considered these concerns, renaming the black safety line as the glottic depth mark. ${ }^{\mathrm{A}}$ As superiority of one marking convention over another has not been proven, the revised ISO standard stipulates that the distance between the glottic depth mark and the TT tip be marked on the unit package, as shown in the Figure.

The correct use of the glottic depth mark requires knowledge of the changes in airway length during

S. Awsar, MD · K. Brown, MD ( $\square)$

Department of Anesthesia, McGill University Health Centre,

Montreal Children's Hospital, Montreal, QC, Canada

e-mail: Karen.brown@mcgill.ca development. In 12 infants (aged zero to two years), Griscom and $\mathrm{Wohl}^{2}$ reported the airway length between the vocal cords and carina (Length $\mathrm{VC}_{\mathrm{C}}$ ) to be $5.4 \mathrm{~cm}$. In 56 infants and toddlers, Sirisopana et $a .^{3}$ used their data to derive the following formula: Length $\mathrm{VC}-\mathrm{C}(\mathrm{cm})=5.3+$ 0.05 age (months); these values were consistent with those measured during bronchoscopy ${ }^{4,5}$ (Table).

In preterm infants, Loew and Thibeault ${ }^{1}$ marked the black safety line $2.2 \mathrm{~cm}$ from the tip of the smallest (internal diameter $2.5 \mathrm{~mm}$ ) uncuffed TT. In a study of 114 fetal autopsies, Rigo and Fayoux ${ }^{6}$ measured the length of the airway between the vocal cords and the mid trachea and reported this length, in millimeters, to be $2.8+0.62$ gestational age (weeks); estimates that were $4.3 \mathrm{~mm}$ shorter than those reported by Loew and Thibeault.

Flexion and extension of the neck can move the TT tip 0.5 to $1 \mathrm{~cm}$ in the caudad and cranial direction, respectively. In $2 \%$ of intubations, Mariano et al. ${ }^{7}$ reported that positioning the double black safety line of Sheridan ${ }^{\mathrm{TM}}$ uncuffed TTs (Hudson RCI@); Temecula, CA, USA) at the level of the vocal cords, located the TT tip within $0.5 \mathrm{~cm}$ of the carina (observed via fluoroscopy). During neck flexion, such a low insertion depth risks endobronchial intubation. In $45 \%$ of the intubations, the TT tip was above the sternoclavicular junction (observed via fluoroscopy). During neck extension, such a high insertion depth risks accidental extubation.

Thus, the correct use of the glottic depth mark requires: 1) knowledge of the developmental changes in the airway length, 2) expert judgment to determine the optimal insertion depth, 3) technical expertise to optimally

\footnotetext{
A International Standard ISO-5361: Tracheal tubes and connectors. Geneva, Switzerland: International Organization for Standardization; 2016.
} 
Figure Example of a size 2.5 (left) and 3.0 (right) Shiley ${ }^{\mathrm{TM}}$ uncuffed tracheal tube (TT) Covidien $^{\mathrm{TM}}$, Mansfield, MA, USA). Each TT has insertion depth marks printed (in $\mathrm{cm}$ ) along the length of the TT. In addition, each TT has two glottic depth marks printed on the distal end. The package inserts indicate the location (in $\mathrm{mm}$ ) of the glottic depth marks $\mathrm{A}$ and $\mathrm{B}$ from the tip of the TT

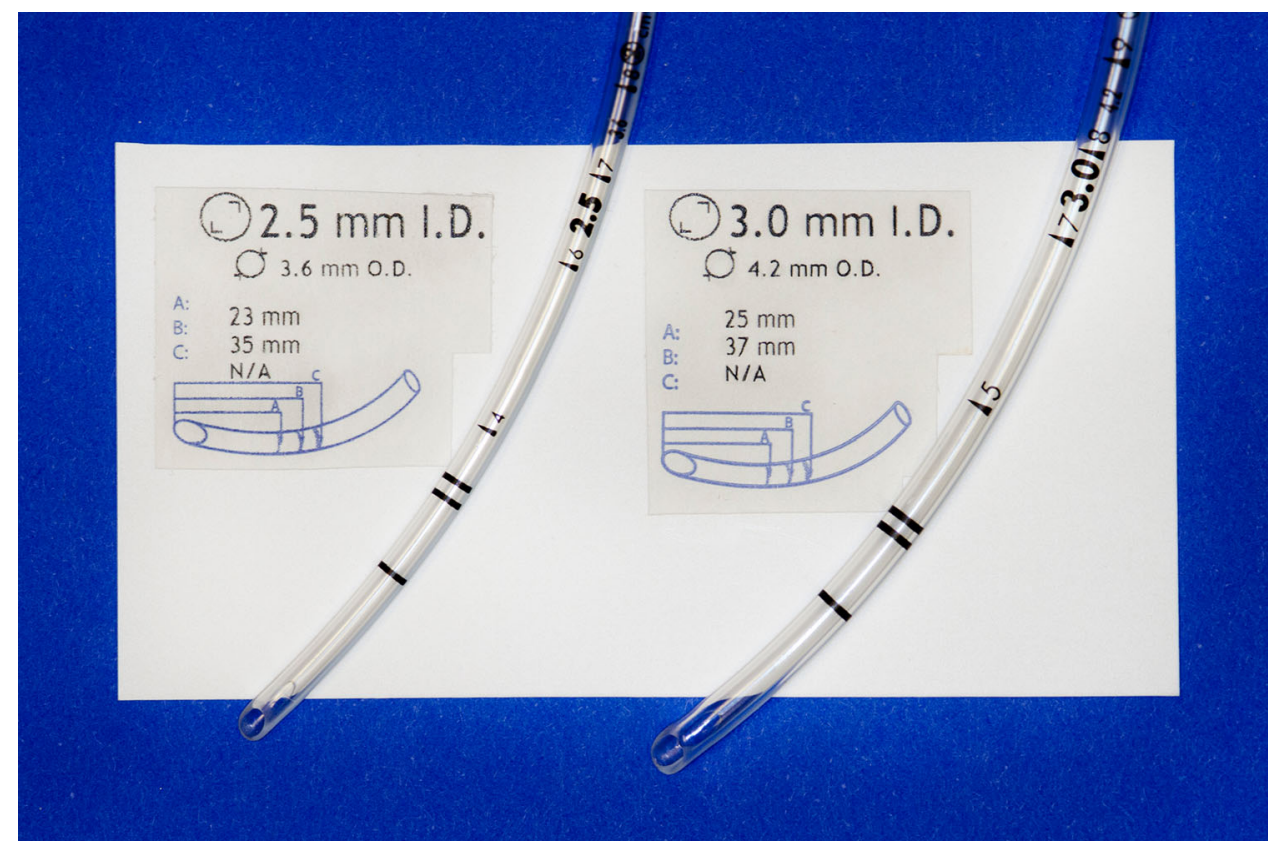

Table Distance in airway length between the vocal cords and carina in infants and children measured from computed tomography and bronchoscopy

\begin{tabular}{|c|c|c|c|c|}
\hline \multirow{2}{*}{$\begin{array}{l}\text { Method } \rightarrow \\
\text { Age }\end{array}$} & \multicolumn{2}{|c|}{ Computed tomography } & \multirow{2}{*}{$\begin{array}{l}\text { Rigid bronchoscopy } \\
\text { Range }^{4}(\mathrm{~cm})\end{array}$} & \multirow{2}{*}{$\begin{array}{l}\text { Flexible bronchoscopy } \\
\text { Range }^{5}(\mathrm{~cm})\end{array}$} \\
\hline & Mean $(\mathrm{SD})^{2}(\mathrm{~cm})$ & $\operatorname{Range}^{3}(\mathrm{~cm})$ & & \\
\hline Birth-3 months & $5.4(0.7)$ & $5.3-5.5$ & $5.0-7.5$ & $3.8-5.9$ \\
\hline 3-6 months & & $5.5-5.6$ & $5.5-8.0$ & \\
\hline $6-12$ months & & $5.6-5.9$ & $5.0-9.0$ & \\
\hline 12-18 months & & $5.9-6.2$ & $7.0-9.0$ & $4.5-6.7$ \\
\hline $2 \mathrm{yr}<4 \mathrm{yr}$ & $6.4(0.5)$ & $7.1-7.4$ & - & $5.0-7.5$ \\
\hline
\end{tabular}

Data were derived and adapted from Griscom and Wohl, ${ }^{2}$ Sirisopana et al., ${ }^{3}$ Fearon and Whalen, ${ }^{4}$ and Weiss et al. ${ }^{5}$ SD $=$ standard deviation

position the glottic depth mark, and 4) knowledge of the specific manufacturer's TT markings on the unit package, all while documenting the corresponding insertion depth mark at the lip or nares.

Conflicts of interest None declared.

Editorial responsibility This submission was handled by Dr. Hilary P. Grocott, Editor-in-Chief, Canadian Journal of Anesthesia.

\section{References}

1. Loew A, Thibeault DW. A new and safe method to control the depth of endotracheal intubation in neonates. Pediatrics 1974; 54 : 506-8.

2. Griscom NT, Wohl ME. Dimensions of the growing trachea related to age and gender. AJR Am J Roentgenol 1986; 146: 233-7.
3. Sirisopana M, Saint-Martin C, Wang NN, Manoukian J, Nguyen $L H$, Brown KA. Novel measurements of the length of the subglottic airway in infants and young children. Anesth Analg 2013; 117: 462-70.

4. Fearon B, Whalen $J S$. Tracheal dimensions in the living infant (preliminary report). Ann Otol Rhinol Laryngol 1967; 76: 965-74.

5. Weiss $M$, Gerber AC, Dullenkopf A. Appropriate placement of intubation depth marks in a new cuffed paediatric tracheal tube. $\mathrm{Br}$ J Anaesth 2005; 94: 80-7.

6. Rigo V, Fayoux P. Distances from vocal cords to mid-trachea for optimizing endotracheal tubes depth markers according to gestational age. Paediatr Anaesth 2018; 28: 361-6.

7. Mariano ER, Ramamoorthy C, Chu LF, Chen M, Hammer GB. A comparison of three methods for estimating appropriate tracheal tube depth in children. Paediatr Anaesth 2005; 15: 846-51.

Publisher's Note Springer Nature remains neutral with regard to jurisdictional claims in published maps and institutional affiliations. 